radiotherapy alone were asked their opinions about their treatment, five described it as having been "very severe," "very unpleasant," "very rough," "horrible," and "terrible." At least half of the 23 patients, however, had no particular complaints about their treatment. Reassurance by the radiographers seemed to allay the fears of some of them. One patient said that she felt insecure after completing her treatment because she was no longer getting frequent check ups. On the whole psychological upset associated with radiotherapy seemed to be short lived and did not usually result in increased ratings of anxiety or depression at three months.

Although most patients who did not have radiotherapy interpreted their lack of postoperative treatment favourably, there were notable exceptions. A few became anxious because they had not received further treatment, but unlike those receiving radiotherapy they attended clinics infrequently after operation so that there were fewer opportunities to seek reassurance or support. For example, one patient feared that her illness was too serious to justify any further intervention. She began to experience panic attacks, which she interpreted as a sign of metastatic disease; several weeks elapsed before she was reassured. Interestingly, Fallowfield et al recently reported that certain patients who had had breast conservation instead of mastectomy became anxious because they feared that treatment had been inadequate, and they emphasised the need for counselling in patients treated conservatively. ${ }^{24}$

This study confirms that a substantial minority of patients experience psychological morbidity after mastectomy, though perhaps of less degree than that reported in previous studies. ${ }^{3}$ Postoperative radiotherapy is sometimes very unpleasant and is associated with an increased incidence of physical symptoms and impaired social functioning. Compared with no postoperative treatment, however, radiotherapy does not seem to induce an excess of depression or anxiety. The psychological morbidity induced by a three week course of radiotherapy after mastectomy is of short duration and is probably overshadowed by the emotional distress associated with fear of cancer and its consequences.

This study was supported by grants from the Cancer Research Campaign. We thank the patients for their cooperation, and members of the division of surgery, Victoria Infirmary, Glasgow, and Drs Agnes Russell and Tim Habeshaw of the Institute of Radiotherapeutics and Oncology, Western Infirmary, Glasgow, for permission to interview patients under their care.
Dr Peter Maguire, University of Manchester, kindly allowed us to use his rating scales.

\section{References}

1 Anonymous. Postoperative radiotherapy in breast cancer [Editorial]. Br Med f 1981;282:1498-9. 2 Gazet J-C, Rainsbury RM, Ford FT, Powles TJ. Survey of treatment of primary breast cancer in Great Britain. Br Med f 1985;289:1793-5.

3 Morris T. Psychological adjustment to mastectomy. Cancer Treat Rev 1979;6:41-61.

4 Hughson AVM, Cooper AF, McArdle CS, Smith DC. Psychological impact of adjuvant chemotherapy in the first two years after mastectomy. Br Med $\mathcal{F} 1986 ; 292: 1268-71$.

5 Maguire GP, Tait A, Brooke M, Thomas C, Howat JMT, Sellwood R. Psychiatric morbidity and physical toxicity associated with adjuvant chemotherapy after mastectomy. $\mathrm{Br}$ Med $\mathrm{J}$ 1980;281:1179-80.

6 Holland J, Rowland J, Lebovits A, Rusalem R. Reactions to cancer treatment: assessment of the emotional response to adjuvant radiotherapy as a guide to planned intervention. Psychiatr Clin North Am 1979;2:347-57.

7 Maguire P. The psychological and social sequelae of mastectomy. In: Howells JG, ed. Modern perspectives in the psychiatric aspects of surgery. New York: Bruner Maisels, 1976:390-421.

8 Silberfarb PM, Maurer LH, Crouthamel C. Psychosocial aspects of neoplastic disease. Functional status of breast cancer patients during different treatment regimens. Am f Psychiatry Functional status

9 Gyllensköld K. (Transl Crampton P.) Breast cancer-the psychological effects of the disease and its treatment. London and New York: Tavistock Publications, 1982:145-212.

10 Hughes J. Emotional reactions to the diagnosis and treatment of early breast cancer. $\mathcal{F}$ Psychosom Res 1982;26:277-83.

11 Maguire GP, Lee EG, Bevington DJ, Küchemann C, Crabtree RJ, Cornell C. Psychiatric problems in the first year after mastectomy. Br Med f 1978;i:963-5.

12 Snaith RP, Bridge GW, Hamilton $M$. The Leeds scales for the self assessment of anxiety and depression. Br f Psychiatry 1976;128:156-65.

13 Goldberg DP. Manual of the general health questionnaire. Windsor: NFER Publishing, 1979.

14 Eysenck HJ, Eysenck SGB. Manual of the Eysenck personality inventory. London: University of London Press, 1964.

15 Raven JC. Guide to using the Mill Hill vocabulary scale with the progressive matrices scale. London: Lewis, 1958.

16 Peck DF. The conversion of progressive matrices and Mill Hill vocabulary raw scores into deviation IQ's. $\mathcal{F}$ Clin Psychol 1970;26:67-70.

17 McArdle CS, Crawford D, Dykes EH, et al. Adjuvant radiotherapy and chemotherapy in breast cancer. Br $\mathcal{J}$ Surg 1986;73:264-6.

8 Cohen J. Weighted kappa: nominal scale agreement with provision for scaled disagreement or partial credit. Psychol Bull 1968;70:213-20.

9 Armitage P. Statistical methods in medical research. Oxford: Blackwell Scientific Publications, 1971: 129-31.

20 Morris T, Greer HS, White P. Psychological and social adjustment to mastectomy: a two-year follow-up study. Cancer 1977;40:2381-7.

21 Greer S. Cancer: psychiatric aspects. In: Granville-Grossman K, ed. Recent advances in clinical psychiatry. Edinburgh: Churchill Livingstone, 1985:87-104.

22 Peck A, Boland J. Emotional reactions to radiation treatment. Cancer 1977;40:180-4.

23 Forester BM, Kornfeld DS, Fleiss J. Psychiatric aspects of radiotherapy. Am 7 Psychiatry 1978;135:960-3.

24 Fallowfield LJ, Baum M, Maguire GP. Effects of breast conservation on psychological morbidity associated with diagnosis and treatment of early breast cancer. Br Med F 1986;293:1331-4.

(Accepted 2 April 1987)

\title{
Ovarian neoplasms, functional ovarian cysts, and oral contraceptives
}

\author{
MARTIN VESSEY, ALISON METCALFE, CLIVE WELLS, KLIM MCPHERSON, \\ CAROLYN WESTHOFF, DAVID YEATES
}

\begin{abstract}
The incidence of ovarian neoplasms and functional ovarian cysts diagnosed at laparotomy or laparoscopy among the 17000 women taking part in the Oxford Family Planning Association contraceptive study was investigated. Epithelial cancer of the ovary was only $25 \%$ as common among those who had ever taken oral contraceptives as those who had never done so (95\% confidence interval $8 \%$ to $67 \%$ ). There was little evidence of any important association between use of oral contraceptives and benign teratoma or cystadenoma. Functional cysts of the ovary occurred much less commonly in women who had recently (in the six months preceding diagnosis) taken combined oral contraceptives (but not in those who had taken progestogen only oral contraceptives) than in those who had never taken oral con-
\end{abstract}

traceptives or had taken them in the past. This protective effect was more pronounced for corpus luteum cysts $(78 \%$ reduction; $95 \%$ confidence interval $47 \%$ to $93 \%$ ) than for follicular cysts (49\% reduction; $95 \%$ confidence interval $20 \%$ to $70 \%$ ).

It is estimated that about 28 (95\% confidence interval 16 to 35$)$ operations for functional ovarian cysts are avoided among every 100000 women who take oral contraceptives each year.

\section{Introduction}

The protective effect of combined oral contraceptives against epithelial cancer of the ovary has been described in a series of casecontrol studies. ${ }^{1}$ There is also some evidence that these preparations 
reduce the risk of functional ovarian cysts. ${ }^{23}$ In this paper we review the data concerning these and related conditions that have accumulated in the Oxford Family Planning Association contraceptive study.

\section{Subjects and methods}

The methods used in the study have been described in detail elsewhere. ${ }^{+}$ In brief, 17032 white married women aged $25-39$ were recruited at 17 family planning clinics in different parts of England and Scotland during the period 1968-74. On entry, 9653 (56\%) were taking oral contraceptives, $4217(25 \%)$ were using a diaphragm, and $3162(19 \%)$ were using an intrauterine device. These women are being followed up at the clinics or, when necessary, by post, telephone, or home visiting; the annual lapse rate for reasons other than death or emigration is about $\mathbf{0 . 3 \%}$. Information collected about each woman during follow up is coordinated at each clinic by a research assistant and includes details of pregnancies and their outcome, changes in contraceptive practices, and reasons for referral to hospital as an outpatient or inpatient. Diagnoses on discharge from hospital are confirmed by obtaining copies of discharge summaries or letters.

We started the present analysis by identifying the study records for each woman in whom ovarian cancer, a benign ovarian neoplasm, a functional ovarian cyst, or an ovarian cyst of unknown pathological type had been noted at laparotomy or laparoscopy. We then attempted to divide the women with benign conditions into two categories: those in whom the lesion itself had, as far as we could judge, been responsible for the symptoms and signs that had led to the surgical intervention at which the diagnosis was made (primary diagnosis), and those in whom the lesion had been an incidental finding during some other procedure such as hysterectomy for fibroids or laparoscopic tubal sterilisation (secondary diagnosis). We considered that the lesions in the primary diagnosis group would, in general, be less subject to detection bias and of greater clinical importance than those in the other group.

In addition to reviewing the diagnostic process we also examined each available pathology report. When the report was missing, or no specific histological diagnosis was given, we asked the hospital concerned to provide the relevant slides or blocks, which were then examined by $\mathrm{CW}$. In this way we assigned the great majority of lesions to a specific diagnostic category. It should be noted, however, that some benign lesions seen at laparotomy or laparoscopy were not excised or biopsied; these lesions accounted for most of those categorised as "type unknown." We considered that most would probably be of functional rather than neoplastic type.

When we had completed this review we were able to use information collected routinely during the study to calculate incidences of the different conditions in relation to age, parity, oral contraceptive use, and several other variables. Details of the statistical methods used are reported elsewhere. ${ }^{+}$

\section{Results}

Table I shows the numbers of women in each pathological category subdivided according to whether the diagnosis of the lesion was primary or secondary. The malignant tumours were all primary diagnoses, as were about $70 \%$ of the benign tumours. Functional cysts, on the other hand, especially follicular cysts, were usually secondary diagnoses. A few women had lesions of more than one type.

As a first step in the analysis we examined the relation between each type of ovarian lesion (except for "borderline malignancy" and "other benign tumour," for which the numbers were too small) and age, parity, and age at first term birth. We considered that it might be important to take any confounding effect of these variables into account in our analyses of the influence of oral contraceptive use. Table II gives the figures for primary and

\section{Department of Community Medicine and General Practice, Radcliffe} Infirmary, Oxford OX2 6HE

MARTIN VESSEY, MD, FFCM, professor

ALISON METCALFE, BSC, research assistant

KLIM MCPHERSON, PHD, university lecturer

CAROLYN WESTHOFF, MD, Milbank research fellow

DAVID YEATES, PHD, computer scientist

Nuffield Department of Pathology, John Radcliffe Hospital, Oxford CLIVE WELLS, MB, MRCPATH, clinical lecturer

Correspondence to: Dr Vessey. secondary diagnoses combined, but the findings were essentially the same when primary diagnoses were considered on their own. Although few of the associations reached significance at the $5 \%$ level, certain patterns emerged. Thus for epithelial ovarian cancer there was a strong positive association with age and a hint of a negative association with parity. Benign teratoma was commoner at ages 30-34 than at other ages and also in nulliparous women than parous women. Cystadenomas were commoner in nulliparous women than parous women. Follicular cysts were associated with all three variables: positively with age and parity and negatively with age at first term birth. Corpus luteum cysts and cysts of unknown type showed no clear association with any of the three variables.

We also examined the relation between each type of ovarian lesion and social class, cigarette smoking, and body weight, but there were no consistent relations.

For our main analysis of oral contraceptive use we considered three categories of exposure - namely, no previous use, use within the six months preceding diagnosis ("recent" use), and use only before the six months preceding diagnosis ("past" use). Table III gives the results, both for

TABLE I-Numbers of women in each category

\begin{tabular}{lccr}
\hline & \multicolumn{2}{c}{ Diagnosis } & \\
\cline { 2 - 3 } Lesion & Primary & Secondary & Total \\
\hline Epithelial carcinoma & 14 & & 14 \\
Epithelial tumour of borderline malignancy & 2 & & 2 \\
Benign teratoma & 36 & 11 & 47 \\
Cystadenoma & 29 & 12 & 41 \\
Other benign tumour & 3 & 6 & 9 \\
Follicular cyst & 27 & 87 & 114 \\
Corpus luteum cyst & 25 & 36 & 61 \\
Cyst of unknown type & 11 & 25 & 36 \\
\hline
\end{tabular}

TABLE II-Association between each type of ovarian lesion and age, parity, and age at first term birth (data represent primary and secondary diagnoses combined). Figures are numbers of women, with rates per 1000 woman years in parentheses

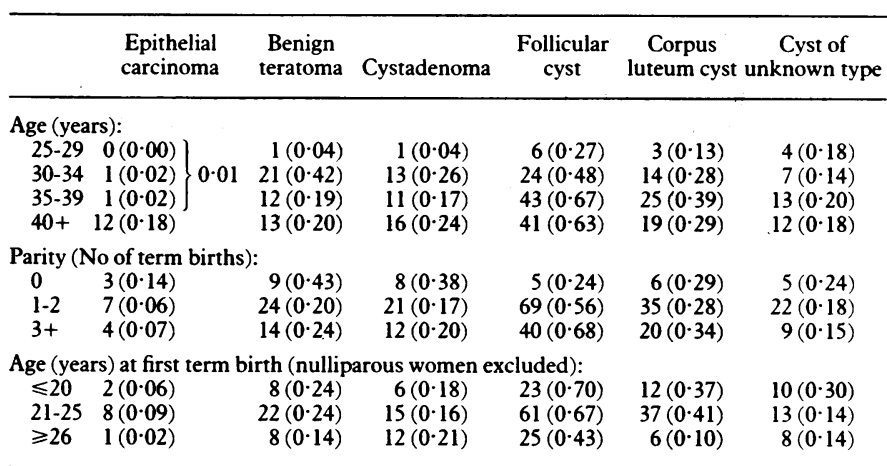

$\chi^{2}$ Tests for heterogeneity and for trend reached significance at the $5 \%$ level only for the following associations: epithelial ovarian cancer and age (ages 25-39v $40+, \chi_{(1)}^{2}=18 \cdot 1$, $p<0.001)$; benign teratoma and age $\left(\chi_{(3)}^{2}=12 \cdot 0, p<0.05\right)$; follicular cyst and age $\left(\chi_{(1)}^{2}\right.$ trend= $4 \cdot 1, p<0 \cdot 05)$; follicular cyst and parity $\left(\chi_{(1)}^{2}\right.$ trend $\left.=3.9, p<0 \cdot 05\right)$.

primary diagnoses considered alone and for primary and secondary diagnoses considered together, adjusted by indirect standardisation for the effects of the variables indicated; this adjustment had only a modest effect.

The incidence of epithelial carcinoma of the ovary among those who had ever used oral contraceptives was only $25 \%$ of that among those who had never done so ( $95 \%$ confidence interval $8 \%$ to $67 \%$ ). The small number of cancers (four) in those who had used oral contraceptives precluded a more detailed examination of this association. There was no suggestion of any association between oral contraceptive use and benign teratoma. Likewise, when the incidence of cystadenoma was contrasted between those who had never used oral contraceptives and those who had ever done so the difference was small and did not approach significance (rates per 1000 woman years: primary diagnosis, never used $0 \cdot 13$, ever used $0 \cdot 15$; primary or secondary diagnosis, never used $0 \cdot 17$, ever used $0 \cdot 22$ ). As table III shows, however, the incidence of cystadenoma was lowest among women who had used oral contraceptives recently and highest among past users of oral contraceptives. An analysis of the risk of cystadenoma in past users by duration of use did not show any association.

Both follicular cysts and corpus luteum cysts were less common among women who had recently used oral contraceptives than among those who had never used them or were past users. For follicular cysts the reduction in risk was $52 \%$ (95\% confidence interval $-11 \%$ to $85 \%$ ) for primary diagnoses and 
TABLE III-Adjusted incidences of various ovarian lesions per 1000 woman years of observation related to oral contraceptive use. (Numbers of affected women in parentheses

\begin{tabular}{|c|c|c|c|c|}
\hline \multirow[b]{2}{*}{ Lesion } & \multicolumn{3}{|c|}{ Oral contraceptive use } & \multirow[b]{2}{*}{$\chi^{2}$} \\
\hline & Never & Recent & Past & \\
\hline Epithelial carcinoma & $0 \cdot 12(10)$ & \multicolumn{2}{|c|}{$0.03(4)$} & $5 \cdot 6^{\star}$ \\
\hline $\begin{array}{l}\text { Benign teratoma: } \\
\text { Primary diagnosis } \\
\text { Primary or secondary diagnosis }\end{array}$ & $\begin{array}{l}0.18(12) \\
0.20(14)\end{array}$ & $\begin{array}{l}0.15(10) \\
0 \cdot 22(14)\end{array}$ & $\begin{array}{l}0.21(14) \\
0.28(19)\end{array}$ & $\begin{array}{l}0.6 \\
1.0\end{array}$ \\
\hline $\begin{array}{l}\text { Cystadenoma: } \\
\text { Primary diagnosis } \\
\text { Primary or secondary diagnosis }\end{array}$ & $\begin{array}{l}0.13(9) \\
0.17(12)\end{array}$ & $\begin{array}{l}0.09(6) \\
0.11(7)\end{array}$ & $\begin{array}{l}0.21(14) \\
0.33(22)\end{array}$ & $\begin{array}{l}3.6 \\
8.8 \text { * }\end{array}$ \\
\hline $\begin{array}{l}\text { Follicular cyst: } \\
\text { Primary diagnosis } \\
\text { Primary or secondary diagnosis }\end{array}$ & $\begin{array}{l}0 \cdot 17(12) \\
0.64(51)\end{array}$ & $\begin{array}{l}0.08(5) \\
0.33(18)\end{array}$ & $\begin{array}{l}0.16(10) \\
0.66(45)\end{array}$ & $\begin{array}{l}2 \cdot 4 \\
7 \cdot 3\end{array}$ \\
\hline $\begin{array}{l}\text { Corpus luteum cyst: } \\
\text { Primary diagnosis } \\
\text { Primary or secondary diagnosis }\end{array}$ & $\begin{array}{l}0.17(12) \\
0.33(25)\end{array}$ & $\begin{array}{l}0.02(1) \\
0.09(5)\end{array}$ & $\begin{array}{l}0.18(12) \\
0.44(31)\end{array}$ & $\begin{array}{c}8 \cdot 6^{\star} \\
13 \cdot 8^{\star \star \star}\end{array}$ \\
\hline $\begin{array}{l}\text { Cyst of unknown type: } \\
\text { Primary diagnosis } \\
\text { Primary or secondary diagnosis }\end{array}$ & $\begin{array}{l}0.06(5) \\
0.19(14)\end{array}$ & $\begin{array}{l}0.02(1) \\
0.11(7)\end{array}$ & $\begin{array}{l}0.06(5) \\
0.22(15)\end{array}$ & $\begin{array}{l}1 \cdot 1 \\
2 \cdot 1\end{array}$ \\
\hline
\end{tabular}

$\chi^{2}$ Based on $1 \mathrm{df}$ for epithelial carcinoma and $2 \mathrm{df}$ for other lesions. ${ }^{\star} \mathrm{p}<0.05, \star \star \star \mathrm{p}<0.001$, all others NS. Variables taken into account in calculating adjusted rates: for epithelial carcinoma, age; for benign teratoma, age and parity; for cystadenoma, parity; for follicular cyst, age, parity, and age at first term birth; for corpus luteum cyst, none; for cyst of unknown type, none.

$49 \%$ ( $95 \%$ confidence interval $20 \%$ to $70 \%$ ) for primary and secondary diagnoses combined. The reduction was, however, much greater for corpus luteum cysts: $92 \%$ ( $95 \%$ confidence interval $57 \%$ to $100 \%$ ) for primary diagnoses and $78 \%$ ( $95 \%$ confidence interval $47 \%$ to $93 \%$ ) for primary and secondary diagnoses combined. The pattern of disease was much the same for the cysts of unknown type, offering support to our view that most of these cysts were functional rather than neoplastic.

Tayob et al recently reported an increased frequency of functional ovarian cysts in women taking progestogen only oral contraceptives compared with those using other methods of birth control. ${ }^{5} \mathrm{We}$ investigated this possibility by calculating the incidence of functional cysts in current users of different methods of contraception. The results were based on very small numbers (table IV) but offered some support to the findings of Tayob et al; certainly there seemed to be an important difference in risk between women taking progestogen only pills and those taking combined pills.

TABLE IV-Incidences of functional ovarian cysts per 1000 woman years of observation related to current contraceptive method. (Numbers of affected women in parentheses)

\begin{tabular}{|c|c|c|c|}
\hline Lesion & $\begin{array}{l}\text { Progestogen only } \\
\text { oral } \\
\text { contraceptive }\end{array}$ & $\begin{array}{l}\text { Other oral } \\
\text { contraceptive }\end{array}$ & $\begin{array}{l}\text { Other or no } \\
\text { method of } \\
\text { contraception }\end{array}$ \\
\hline $\begin{array}{l}\text { Follicular cyst: } \\
\text { Primary diagnosis } \\
\text { Primary or secondary diagnosis }\end{array}$ & $\begin{array}{l}0.52(2) \\
0.78(3)\end{array}$ & $\begin{array}{l}0.06(3) \\
0.21(10)\end{array}$ & $\begin{array}{l}0 \cdot 15(22) \\
0.67(101)\end{array}$ \\
\hline $\begin{array}{l}\text { Corpus luteum cyst: } \\
\text { Primary diagnosis } \\
\text { Primary or secondary diagnosis }\end{array}$ & $\begin{array}{l}0 \\
0 \cdot 26(1)\end{array}$ & $\begin{array}{l}0 \\
0.04(2)\end{array}$ & $\begin{array}{l}0.17(25) \\
0.39(58)\end{array}$ \\
\hline
\end{tabular}

\section{Discussion}

Our data on epithelial carcinoma of the ovary are entirely consistent with those reported from case-control studies conducted in the United States, which showed, on average, about a $50 \%$ reduction in risk in those who had ever taken oral contraceptives. ${ }^{1}$ We are collecting more data to confirm or refute the other main findings obtained in case-control studies-namely, that the protection increases with duration of use of oral contraceptives and that it persists for many years in those who stop taking the pill.

The origin of benign ovarian teratomas is uncertain, but there is evidence that they are parthenogenetic tumours arising from a single germ cell after the first meiotic division. ${ }^{6}$ We found no association between these tumours and oral contraceptive use. We have been able to find only one other study in which the relation between oral contraceptive use and benign teratoma has been reported, the Walnut Creek contraceptive drug study. ${ }^{7}$ Like us the Walnut Creek group found no association; the incidence per 1000 woman years of observation was 0.53 ( 15 cases) in those who had never taken the pill and 0.51 ( 32 cases) in those who had taken oral contraceptives at some time.

Some malignant epithelial tumours of the ovary may develop within cystadenomas. Accordingly we expected that we might see a reduction in the incidence of cystadenoma as well as of ovarian cancer in those taking the pill. This turned out not to be so overall, although our data are compatible with the hypothesis that cystadenomas are to some extent suppressed in women taking oral contraceptives and emerge only after the drugs are stopped. Once again only the Walnut Creek group has provided comparable data on ovarian cystadenoma. ' It found no evidence of a difference in risk when comparing those who had never used the pill with those who had done so (incidences per 1000 woman years of observation 0.47 (12 cases) and 0.47 ( 31 cases), respectively). Unfortunately, the group did not distinguish recent pill users from past pill users so no further comparison can be made between the studies. One conclusion, however, does seem possible: the strong protective effect of oral contraceptives against epithelial cancer of the ovary is not replicated for ovarian cystadenoma. This finding may have implications for work on the aetiology of epithelial cancer of the ovary.

Several groups have studied the relation between oral contraceptive use and functional cysts of the ovary, although none has distinguished between follicular cysts and corpus luteum cysts. The Boston collaborative drug surveillance program found a $\mathbf{9 0 \%}$ reduction in functional cysts in recent users of oral contraceptives compared with non-users ${ }^{2}$; the Royal College of General Practitioners found a $65 \%$ reduction in current users (although it is not clear in that study whether the ovarian cysts were functional or neoplastic) ${ }^{3}$; and the Walnut Creek group found a $40 \%$ reduction in current users. ${ }^{7}$ Our figures are comparable, but the protective effect was much stronger against corpus luteum cysts than against follicular cysts. Furthermore, the protective effect was short lived, disappearing within a few months of the pill being stopped, and did not seem to apply to women taking progestogen only preparations.

Though the prevention of functional cysts found incidentally during laparotomy or laparoscopy is of little consequence to the patient, the prevention of cysts that necessitate surgical intervention is an important benefit of oral contraception. The data given in table III (taking the primary diagnosis figures for follicular cysts, corpus luteum cysts, and cysts of unknown type together) suggest that among every 100000 women using oral contraceptives 12 will undergo such surgical intervention each year compared with 40 among every 100000 women using other methods of contraception. This represents a saving of 28 (95\% confidence interval 16 to 35 ) operations per 100000 women taking oral contraceptives per year.

We thank Mrs C Brice, Mrs P Brown, Mrs D Collinge, Dr L VillardMackintosh, our clinic research assistants, and all the doctors, nurses, and administrative staff working in the family planning clinics for their loyal and enthusiastic support. Dr R H Cowdell provided helpful advice. We are also grateful to the many pathologists who provided review material and to the Medical Research Council for financial support.

\section{References}

1 Vessey M. Exogenous hormones. In: Vessey MP, Gray M, eds. Cancer risks and prevention. Oxford: Oxford University Press, 1985:166-94.

2 Boston Collaborative Drug Surveillance Program. Functional ovarian cysts and oral contraceptives: a negative association confirmed surgically. fAMA 1974;228:68-9.

Royal College of General Practitioners. Oral contraceptives and health. London: Pitman Medical, 1974

4 Vessey M, Doll R, Peto R, Johnson B, Wiggins P. A long-term follow up study of women using different methods of contraception-an interim report. $\mathcal{I}$ Biosoc S $c i$ 1976;8:373-427.

5 Tayob Y, Adams J, Jacobs HS, Guillebaud J. Ultrasound demonstration of increased frequency of functional ovarian cysts in women using progestogen-only oral contraceptives. $\mathrm{Br} \mathcal{J}$ Obstet Gynaecol 1985;92:1003-9.

6 Lindner D, McCaw BK, Hecht F. Parthenogenetic origin of benign ovarian teratomas. $N$ Engl f Med 1975;292:63-6.

7 Walnut Creek Contraceptive Drug Study. A prospective study of the side effects of oral contraceptives. Vol III. Bethesda: National Institutes of Health, 1981.

(Accepted 9 April 1987) 